\title{
NARRATIVAS FEMININAS GUAJAJARA E AKRÃTIKATÊJÊ NO ENSINO SUPERIOR
}

\author{
FEMALE GUAJAJARA AND AKRÃTIKATÊJÊ NARRATIVES \\ IN THE UNIVERSITY
}

\author{
SANTANA, Tatiana de Oliveira ${ }^{1}$ \\ PAIM, Elison Antonio ${ }^{2}$
}

\begin{abstract}
RESUMO
Homens e mulheres dos povos originários ocupam universidades brasileiras pelas recentes políticas de cotas. Com isso, vão provocando estranhamentos, reflexões, desafios e mobilizações nesses espaços que devem promover além da entrada, condições de permanência nos cursos de graduação e em suas bases epistemológicas universais. Nosso texto se localiza deste modo, numa tentativa de abordar este tema buscando compreender pelas narrativas de experiências e memórias, de quatro mulheres de povos originários distintos, discentes de cursos de graduação da Universidade Federal do Sul e Sudeste do Pará (UNIFESSPA). Nas aproximações teóricas convidamos a essa tessitura junto às narrativas femininas uma opção teórico-metodológica benjaminiana baseada em mônadas e o pensamento de alguns autores e autoras, pensando experiências e memórias (BENJAMIN, 2012), representação e interculturalidade (WALSH, 2009).
\end{abstract}

PaLAVRAS-CHAVE: Narrativas femininas; Indígenas; Educação; Mônadas.

\section{ABSTRACT}

Men and women belonging to native peoples occupy Brazilian universities because of recent quota policies. However, they are provoking strangeness, reflections, challenges and mobilizations in these spaces that should promote, beyond the enrollment, conditions of permanence in undergraduate courses and their universal epistemological bases. Our text is an attempt to approach this theme by trying to understand the narratives of experiences and memories of four women belonging to different native peoples, undergraduate students at the Federal University of the South and Southeast of Pará (UNIFESSPA). Benjaminian theoretical-methodological approach based on monads and the thinking of some authors, who think experience and memory (BENJAMIN, 2012) and representation and interculturality (WALSH, 2009).

KEYWORDS: Female narratives; Indigenous: Education: Monads.

1 Pedagoga; Mestre pelo Programa de Pós-Graduação em Educação da UFSC. e-mail: tati_ubuntu@hotmail.com

2 Historiador; Professor do Programa de Pós-Graduação em Educação da UFSC. e-mail: elison0406@gmail.com 


\section{INTRODUÇÃO}

Este texto tem por objetivo apresentar algumas discussões desenvolvidas na pesquisa de Mestrado em Educação intitulada "Narrativas Femininas Guajajara e Akrãtikatêjê no Ensino Superior", no Programa de Pós-Graduação em Educação da Universidade Federal de Santa Catarina - UFSC.

A pesquisa foi realizada a partir das narrativas de experiências e memórias vividas e expressas no âmbito acadêmico de quatro mulheres de povos originários distintos das regiões Sul e Sudeste do Pará, discentes em cursos de graduação da Universidade Federal do Sul e Sudeste do Pará (UNIFESSPA), a partir do período recente do acesso à universidade.

Com viés educativo e histórico, a pesquisa buscou compreender como as memórias e experiências sobre ensino superior se revelam nas vozes femininas das Guajajaras/Tenetehára e da Cacica Gavião/ Akrãtikatêjê, e possibilitando, assim, a legitimação dessas memórias e experiências narradas.

A construção dessas narrativas ocorreu em momentos que definimos como encontros narrativos femininos. Aproximando-nos da sociopóetica, desenvolvemos dispositivos poéticos, objetivando a contação de histórias, cujo tema central seria as experiências nas universidades.

Nas aproximações teóricas, convidamos para essa tessitura, junto às narrativas femininas, o pensamento de alguns autores e autoras que pensam experiências e memórias (BENJAMIN, 2012), hibridismo e cultura (BHABHA, 2013), representação e interculturalidade (WALSH, 2009). Do mesmo modo, embasados no filósofo Walter Benjamin, que apresentou a narração como a faculdade de intercambiar experiências, realizamos um percurso teórico-metodológico baseado em mônadas.

No sentido de melhor apresentarmos nossa argumentação, dividimos o artigo em quatro partes: na primeira abordamos a escolha da opção teórico-metodológica monadológica; em seguida, apresentamos as mulheres de povos originários discentes da Unifesspa, nossos sujeitos de pesquisa; num terceiro momento, orientados pelas narrativas das mulheres Guajajaras e da Cacica Akrãtikatêjê, usando o suporte teórico-metodológico monadológico, evidenciamos suas narrativas sobre a entrada na universidade, nas quais se torna constante determinada categoria: o do estranhamento. Concluímos com as considerações seguidas das referências bibliográficas.

\section{A OPÇÃO TEÓRICO-METODOLÓGICA MONADOLÓGICA}

A forma literária como nos apresentamos diz muito sobre nós e, para tal, optamos pela escolha teórico-metodológica monadológica de escrita e análise das falas das mulheres que fizeram parte dessa pesquisa. 
Partimos da compreensão das mônadas nos diálogos com Benjamin e em consonância com pesquisadoras brasileiras, entre as quais, as historiadoras Maria Carolina Bovério Galzerani, ex-Diretora do Centro de Memória da UNICAMP, e Cynthia Simioni França, que produziu uma pesquisa sobre formação de professores na qual adotou essa opção metodológica e teórica. Também com essa escolha, buscamos referência na educadora Maria Inês Petrucci Rosa, estudiosa de narrativas e currículo.

Walter Benjamin (1994) conceituou mônadas como fragmentos literários, entrecruzadas de subjetividades, carregados de sentimentos e experiências narradas. Nesse sentido, as mônadas podem ser entendidas como "[...] pequenos fragmentos de histórias que juntas exibem a capacidade de contar sobre um todo, muito embora esse todo possa também ser contado por um de seus fragmentos" (ROSA, 2011, p. 203).

A professora Maria Inês Petrucci Rosa, no texto "Narrativas e Mônadas" (ROSA, et al. 2009), refletindo sobre currículo e narrativas como outra possibilidade para uma compreensão de currículo, conceituou mônadas a partir do próprio Benjamin, como uma série de pequenas narrativas, remetendo-se ao texto "Infância em Berlim por volta de 1900". Nessas pequenas narrativas que remetem à infância de Benjamin, foi possível vislumbrar a articulação entre o vivido individual do autor e as esferas sociais mais amplas, valorizando as experiências do passado infantil e ressignificando-as a partir do olhar adulto.

A historiadora Cyntia França, em sua tese de doutorado, desenvolveu um processo teórico-metodológico mergulhado em fragmentos de narrativas orais e escritas de educadores carregados de significados, dos cacos dos miúdos que constituem o todo. Para a autora, "[...] mônadas são minúsculos fragmentos vividos que podem ser lidos na sua singularidade, com a potencialidade de estabelecer relações entre as especificidades" (FRANÇA, 2015, p. 106).

Logo, o trabalho artesão monodalógico do qual Benjamin foi ator, quando propôs que a mônada contém a ideia do mundo, o dizível por ela mesma, representando o fenômeno das suas ideias sobre o estabelecido, sobre 0 experienciado (BENJAMIN, 2011). E por esta linha de pensamento fomos compondo as mônadas sobre a universidade pelas memórias das mulheres que participaram da presente pesquisa, sobre o quê se interrogam nessa experiência.

Ressaltamos que ao trabalharmos com essa opção teórico-metodológica, não o fazemos com o propósito de procurar falhas e críticas ao narrado, ao que foi rememorado, e nem fazer análises exaustivas do narrado, mas sim pensar principalmente nas diferenças que são homogeneizadas no espaço acadêmico, percebendo em que momento ocorreu a visão generalista de que os indivíduos de povos indígenas presentes na universidade são todos iguais. Ainda, discutir as relações da interculturalidade para além das relações de trocas entre culturas, mas de acordo com o pensamento de Catherine Walsh (2009), em que a 
DOI: $10.12957 /$ e-mosaicos.2018.30145

interculturalidade estabelece uma relação de complementaridade entre diferentes realidades e formas de compreender o mundo.

Partindo das narrativas de memórias femininas indígenas na universidade, adotamos, portanto, como metodologia, a construção de mônadas. Essa opção metodológica nos remete à representação, à qual Spivak (2010) se debruçou, quando afirmou que, em relação às mulheres emudecidas, é necessário, como dito, aprender a falar "com" e não "para", onde "o teórico não representa o falar pelo grupo oprimido" (SPIVAK, 2010, p. 39).

Outro ponto importante a destacar quando fizemos a opção teórica monadológica é que não o fizemos no sentido de dar voz - pois essas mulheres se mobilizam e carregam tatuadas nos seus corpos, gestos e comportamentos que refletem suas resistências -, mas sim registrar, como forma literária, evidenciando suas memórias e experiências. Percebemos a necessidade de evidenciar essas falas carregadas de significados, para as quais muitas vezes a universidade "tampa seus ouvidos", pelos processos violentos de homogeneização e algumas discussões relacionadas às diversas culturas.

Ressaltamos também que as reminiscências ditas se articulam com as nossas subjetividades e poesias que se mostram, sem ser necessária a comprovação das fontes, mas acreditando que somos o que narramos, pois, nesse narrar vamos nos fazendo (PAIM, 2005). Assim, apresentamos as narrativas numa ordem, não de importâncias de falas, mas pelo desencadear dos contatos, das primeiras conversas e a partir de suas narrativas.

Figura 1: Nayara Guajajará

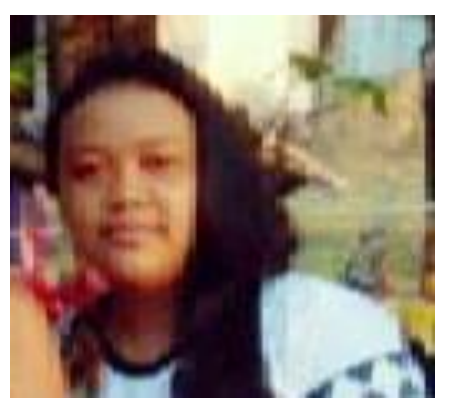

Fonte: Acervo da pesquisadora, 2015

Eu sou Nayara Guajajará, indígena. Sobre a nossa língua Guajajará, entendo algumas coisas. Tanto consigo entender como escrever. Meu sonho é terminar e voltar pra aldeia. Deus me livre ficar aqui na cidade, e nem no Município de Itupiranga, eu só estou na cidade mesmo pra terminar meu curso, senão estaria era lá em casa. Se 
tivesse um serviço pra mim, ficaria na aldeia, pois é muito difícil você crescer morando na aldeia e depois de adulto vir morar na cidade. Queria que a Karla, minha filha, estudasse lá na aldeia, com as outras crianças, aprendendo a língua, mas devido as dificuldades do momento, ela tem que ficar aqui comigo. Quando comecei como bolsista no projeto do PIBID, o pessoal da aldeia pensou que eu estava trabalhando aqui em Marabá e que não voltaria para a aldeia. Isso me incomoda. Tenho um compromisso com a aldeia. Eu posso não ter nascido lá, mas minha família está lá, então eu vou estudar, me formar e eu quero trabalhar lá. (Nayara Guajajara. Entrevista, 2016).

Nayara também nos presenteia, apresentando-se em sua língua:

Aixak atar herekohaw wà.

Herer Nayara Pereira Ventura Guajajara iheà. Umuauze Tentehar Guajajara. Hezemu'e haw Geografia rehe no Marabá UNIFESSPA pezote no. Ereko haw tentehar rekohaw pe Guajanaira. Itupiranga iziwà rehe. 27 kwarahy areko. Areko hememyr no 5 kwarahy uwereko a'e à no. Rerekohaw marabá pe areko na'i rui hekypy'ir wà pitey hekywyr her George a'e no, her Nayanne a'e no, Gisele a'e no, Elenara a'e no.

Minha apresentação:

Meu nome é Nayara Pereira Ventura Guajajará. Pertenço ao povo Guajajará. Sou estudante do curso de Geografia pela UNIFESSPA Universidade Federal do Sul e Sudeste do Pará, campus de Marabá. Moro na aldeia Guajanaíra, no município de Itupiranga - Pará. Tenho 27 anos. Tenho uma filha de cinco anos. Em Marabá, moro com meus 4 irmãos, George, Nayanne, Gisele e Elenara.

\section{Raquel GuajajarÁ, eStudANTE de CiÊnCias Sociais da UNIFESSPA}

\section{Figura 2: Raquel Guajajará}

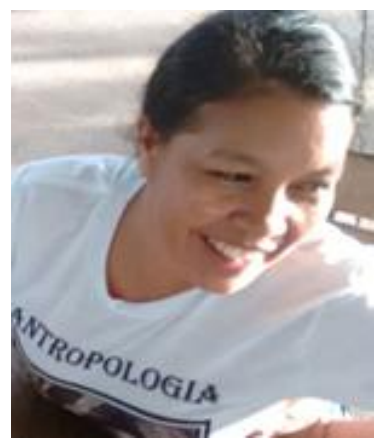

Fonte: Acervo da pesquisadora, 2015. 
Meu nome é Raquel Guajajará, o mesmo nome que me chamam na aldeia. Não nasci na aldeia, nasci numa roça próxima, e aos 16 anos me mudei para aldeia; nunca imaginava sair de lá, pois nunca tinha visto um indígena sair da aldeia para outro estado. Meu pai é indígena e minha mãe negra, meu pai foi criado na cidade e depois de adulto voltou para aldeia. A aldeia sempre foi muito perto da cidade, as pessoas tinham a costume de ir lá caçar, pescar, passear. Um dia, meu pai ainda bem jovem estava fazendo farinha; a minha mãe passou e ele disse: "Essa mulher vai ser minha esposa". Depois eles conversaram e ele carregou ela pra uma cidade perto da aldeia chamada Monção. Minha mãe não tinha pai, ela foi criada pelo meu avô. O Povo Guajajará tem a língua como diferente, embora sejam diferentes dos Tembé, mas nunca parei pra pensar o que diferencia o Povo Guajajará, acho que deve ser a pintura, que não sei como explicar, mas se ver eu reconheço. A minha filha pinta, eu não pinto. Fazia artesanato, mas não faço mais, pois tem muita coisa pra ler, escrever, tarefas domésticas e por isso não faço mais. Eu me acho desinteressada dos estudos, vejo que quando vou fazer uma prova não me sinto segura, eu estudo, estudo, mas me sinto muito fraca. Não tenho computador em casa, então leio muito os textos, mas na hora que vou apresentar os seminários e fazer a prova, sou péssima. As pessoas até riem de mim quando é o meu dia de apresentar e fico tensa. (Raquel Guajajara. Entrevista, 2016).

\section{NAYANE GUAJAJARÁ, ESTUDANTE DO CURSO DE DiREITO DA UNIFESSPA}

\section{Figura 3: Nayane Guajajará}

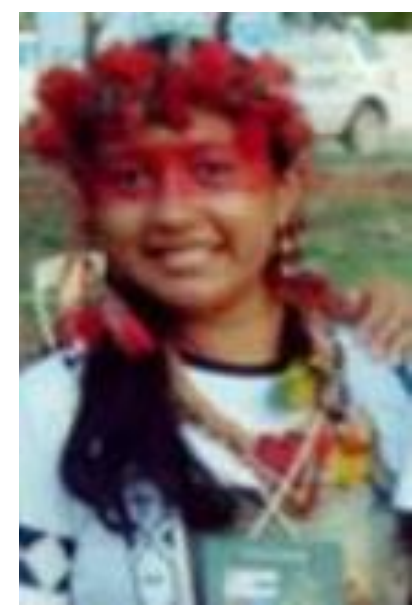

Fonte: Acervo da pesquisadora, 2015. 
Meu nome é Nayane, sou do povo Guajajará. Moro na aldeia Guajanaíra, município de Itupiranga. Estudei desde a Alfabetização até o Ensino Fundamental, até a sétima série, na aldeia. Aí depois estudei na cidade. Só que antes morava na aldeia Terra Preta, no Maranhão. Vim para o Pará no ano de 2007. Chegando na aldeia, a gente veio logo pra morar na cidade, em Itupiranga, porque na aldeia não tinha o Fundamental de $5^{a}$ até a $8^{a}$ série. Não tinha, era necessário se deslocar pra cidade, então a gente veio. Estudei a $8^{a}$ série até o Ensino Médio. Sempre pensei em fazer vestibular. Uma área que eu sempre quis era a Nutrição, nunca pensei em fazer Direito, nunca na minha vida. Só quando criança que contamos aquela coisa sem saber mesmo. Mas nunca pensei em fazer Direito não. Não sou casada. Mas, é difícil pras pessoas que são casadas ou tem filhos sair pra estudar. Porque se vier pra estudar tem que trazer a família inteira (risos) (Nayara Guajajara. Entrevista, 2016).

\section{KÁTIA, A PRIMEIRA CACICA MULHER DO POVO GAVIÃO AKRÃTIKATÊJÊ, EX-ESTUDANTE DO CURSO DE LETRAS DA UNIFESSPA}

Figura 4: Kátia Gavião

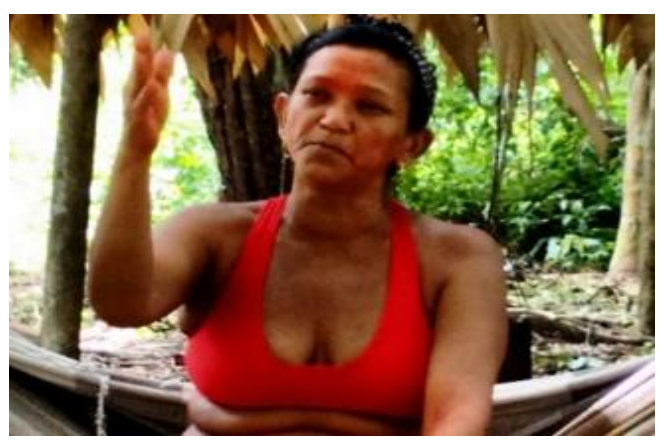

Fonte: Acervo da pesquisadora, 2015.

Sou Tônkyre Akrãtikatêjê, Kátia. Às vezes a gente se lamenta, colocando dificuldade nas coisas que não tem. Cada um de nós tem uma visão, pensamento diferente, meu pai me educou e não cursou nenhuma faculdade, ele me dizia que pedia ao nosso Deus da sabedoria. $O$ povo indígena cada um tem um saber, assim como nós do Povo Akrãtikatêjê temos esse dom, essa sabedoria. Meu pai foi Cacique aos dez anos, dentro da mata, mata virgem, índio brabo, não falava português. Com quatorze anos meu pai veio estudar, com os americanos, falou português. Eu, com nove anos de idade, morando na aldeia em Tucuruí, que nos chamava Kyikatêjê, que é a ladeira, cabeça, monte, já me entendi lá, vendo meu povo tudo reunido; eu vi também quando a barragem chegou e destruiu tudo. Tudo isso é 
uma imagem que ficou na minha cabeça. As ameaças, quando meu pai quase foi morto; ali meu pai me preparou. Ele dizia pra mim que queria que eu fosse homem, mas aí eu nasci mulher, e ele me dizia "tudo que um homem faz tu vai fazer, por que eu vou te ensinar". Muito cedo ele me ensinou a atirar, montar e desmontar espingarda, colocar malhadeira, pegar peixe, vender, não tinha horário, meia noite, quatro da manhã, eu já estava no rio pra pescar, então minha vida foi assim, fazendo roça, fazendo farinha, trabalhando na roça com meus irmãos, meu pai, com meu povo. Para eu ser Cacica foi nessa luta, acompanhando meu pai; meu pai ia pescar e eu junto, onde ele me dizia: "Se cupem me matar tu vai embora, grava o número da Funai na cabeça. Se escapar, cai na água, nada e vai embora, avisa ao povo, pois acho que vão me matar por causa da terra". E meu pai me dizia: "Ó, tá vendo minha luta, tá vendo meu sofrimento". Aí chegou um tempo que nós morávamos bem dentro da mata, dez quilômetros só mata e encheu o caminho por onde nos íamos. Os posseiros cortaram a mão dele, queriam matar, cortar o pescoço, aí ele botou a mão, pegou e cortaram, caiu no chão, foi daí que eu esperei meu pai. Eu tive um sonho que contei pra ele, no sonho muito índio chegava e o senhor pintado com flecha; eu contei o sonho, ele foi embora e disse: "Cuida dos teus irmãos". Eu já tinha dez anos, cuidei dos meus irmãos, eu pescava e cuidava dos meus irmãos só com peixe e farinha, não tinha arroz não tinha feijão, e quando meu pai passou três meses no hospital, fui eu que cuidei deles, eu que fui o homem da casa, eu tinha responsabilidade. Desde lá ele já viu a minha luta; quando ele voltou do hospital, ele estava bem fraco, e ficava olhando a minha luta. Meu pai sempre dizia que uma liderança não pede pra ser uma liderança, um cacique não pede pra ser cacique, são as comunidades que escolhem, os mais velhos vêem a atitude, o desempenho daquela pessoa, assim como vê o cupem, os estudiosos que estão na rua, e tem que estudar também. Ninguém pede pra ser cacique, pra ser liderança, nasce com o dom na veia, eu tinha muita sabedoria, o que eu via o meu pai fazendo eu continuava fazendo, eu caçava, tirava açaí com meus irmãos (Kátia Akrãtikatêjê. Entrevista, 2016).

Essas narrativas femininas, carregadas de significados, trazem alguns aspectos a serem considerados. Inicialmente destacamos: o que é ser "indígena" na atual sociedade? Qual o compromisso com meu povo?

Essas mulheres, marcadas em diferentes tempos e signos por interpretações homogeneizadoras e estereotipadas, ora baseadas em interpretações romantizadas, que aparecem nos livros didáticos, ora descaracterizadas como sem cultura, são cobradas, pela sociedade envolvente, pela sua identidade. No entanto, essa cobrança, na reflexão de um dos teóricos da cultura, Homi Bhabha (2013, p. 61), faz-se, no conceito da diferença cultural, que para o autor "[...] concentra-se no problema da ambivalência da autoridade cultural: a tentativa de dominar em nome 
e-Mosaicos - Revista Multidisciplinar de Ensino, Pesquisa, Extensão e Cultura do Instituto de Aplicação Fernando Rodrigues da Silveira (CAp-UERJ)

V. 7 - N. 14 - ABRIL 2018 - ISSN: 2316-9303

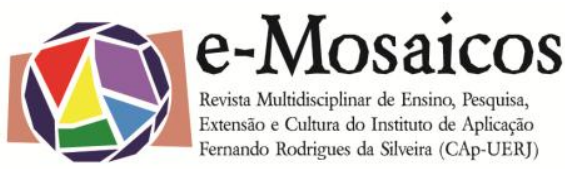

DOI: $10.12957 /$ e-mosaicos.2018.30145

de uma supremacia cultural que é ela mesma produzida apenas no momento da diferenciação".

Logo, faz-se necessário repensar as perspectivas de identidade e cultura, visto que nenhuma cultura é unitarista em si mesma. Pois ocorre em espaços de trocas e de resistências; espaços esses que são ambivalentes e contraditórios, formando um terceiro espaço, demonstrando que são empíricos e híbridos, não sendo possível afinal essas mulheres ficarem marcadas em aspectos e interpretações fechadas de determinadas identidades e culturas, tais como são apresentadas no pensamento colonizador comum. Esse pensamento, na tentativa de reconhecer a diferença, termina homogeneizando, não considerando os hibridismos e as trocas.

Portanto, os processos de colonização são vivenciados de diferentes formas por essas mulheres. Um deles se expressa mais em algumas narrativas: o fato de algumas delas não falarem mais a língua materna, mas resistem e fazem questão de enaltecer suas linguagens próprias, mesmo que essa tenha sido proibida num passado histórico não muito distante. Os desafios que sentem ao estarem na cidade e o compromisso com seu povo também são fortes nessas narrativas. Estar na universidade não representa o único desafio, o único peso, pois têm consciência que o objetivo maior está em contribuir com seu povo.

O sentimento de pertencimento a uma cultura, uma cultura híbrida, está presente nas narrativas femininas; o saber reconhecer-se como parte de uma cultura, reconhecer algo que só quem é daquela comunidade reconhece facilmente, seja uma pintura, um objeto da arte indígena, a forma de falar.

Alguns saberes, mesmo que soterrados pela escolha de estar na universidade, vivendo na pressão de dar conta das leituras e trabalhos acadêmicos, não deixam de existir, ressurgem, ainda estão presentes, por exemplo, na filha que sabe fazer a arte indígena, que na cultura Guajajará é tarefa específica das mulheres.

Fanon (2008), ao ser indagado se os negros eram mais inteligentes que os brancos, respondia que inteligência nunca salvou ninguém: "[...] pois se é em nome da inteligência e da filosofia que se proclama a igualdade dos homens, também é em seu nome que muitas vezes se decide seu extermínio" (p. 43). Fizemos essa referência no sentido de questionar: quem está preparado para estar na universidade? Se respondermos por uma lógica pautada no conhecimento eurocêntrico, sabemos das fronteiras que irão surgir, o que de certa forma legitima e torna esse espaço tão seletivo. Quando, nas narrativas acima, a indígena expressou o sentimento de inferioridade ao apresentar seus trabalhos e as dificuldades no entendimento das leituras dos textos acadêmicos, culpabilizou-se!

De acordo com pensadores decoloniais latino-americanos, como Enrique Dussel (2010) e Walter Mignolo (2002), esse sentimento de subordinação é próprio do mecanismo de controle do saber e da sociedade colonizadora, que desvaloriza, culpabiliza e invisibiliza outras formas de conhecimento, outras línguas, outras culturas, outras religiões, outras formas de organização social. Essas invisibilizações e processos de dominação do saber e do ser são tratados também por Maria 
DOI: $10.12957 /$ e-mosaicos.2018.30145

Lugones (2015), em seus estudos sobre e intersecções de raça, gênero e a colonialidade de gênero. Neles, defendeu que a dominação de gênero é também uma forma de colonização e nos lembrou que mesmo nos debates de gênero, é necessário pensar a mulher negra, a mulher de um povo originário e o transexual, que fogem às relações binária de homem e mulher branca, macho-fêmea, americanizada, mas de mulheres carregadas de subjetividades e especificidades que precisam ser conhecidas, e não somente homogeneizadas, transformadas umas pelas outras.

Portanto, para a compreensão das representações dessas narrativas femininas, percebemos a necessidade de viajar em entremundos, conceito abordado pela autora, pela necessidade de não colonizar as experiências de gênero dessas mulheres dos povos originários, mas aprender sobre como se situam no mundo; como fazem suas resistências, como constroem suas barricadas, sem generalizar, a partir do nosso olhar de não indígena, mas nos deslocando de nossas certezas e percebendo suas formas de existir, sem dar ênfase somente à sua subalternidade, que para Gayatri Spivak (2010) é promovida social e politicamente.

\section{SOBRE A CHEGADA À UNIVERSIDADE: ESTRANHAMENTOS}

Entrei na Universidade, só que foi um choque muito grande. Pensei que não ia dar conta. Quase que entrei em desespero porque era muito difícil, diferente. Ainda mais que no ensino médio não temos assim um ensino de qualidade, porque não temos muitas das coisas que é preciso ver. Porque vai ser necessário no ensino superior, a gente não vê direito. Principalmente quando se vai fazer o curso de Direito. A gente tem que ter uma base na área de filosofia muito grande. Porque, praticamente, o curso vai decorrer baseado nesses filósofos. Então minha dificuldade foi essa. Mas só que depois a gente vai se esforçando, se adaptando. O curso de direito pode ajudar meu povo em assuntos que a gente não sabe. A gente fica dependendo muito das pessoas de fora pra resolver muitos problemas. Que nem agora, recentemente. Eu fiquei bem preocupada, meu Deus! Como resolver um problema lá na escola da aldeia, que foi uma questão de educação bilíngue. A secretaria de Educação não queria contratar um professor e tal, por conta que a professora lá da aldeia, que é minha mãe, passou no concurso e que seria chamada, só que ela não sabe falar na Língua, só entende. Ela não tem domínio. Aí ele não quis e queria que ela dividisse a carga horária de lá com ela, enquanto concursada. Aí eu fiquei, será que isso é correto? Será que isso tá na lei? Tem lei que garante isso, de divisão de carga horária? Porque no concurso tá dizendo no edital isso. Ele quer fazer ao contrário o que tá no edital. Aí, então, são situações assim que é necessário a gente ter uma base jurídica, porque se a gente não tiver a gente é enrolado (Nayane Guajajara. Entrevista, 2016). 
[...] nem sabia o que era a universidade, ouvi falar das provas que fazia todos os anos pra somar e dar a nota de um curso, sempre tinha vontade de fazer mas não tinha os 40 reais da inscrição. [...] vou me inscrever no vestibular e sair dessa vida, mas no primeiro ano não deu certo, fiz a prova, não passei na entrevista, até que na prova eu fiz pra ciências naturais, na redação tirei 9 , fui até bem, mas na entrevista fui péssima. [...] Em novembro/dezembro de 2009, a Funai, mandou informativo pra aldeia Guajanairá, estava grávida, e olhei os cursos e me apaixonei, já estava nos meses finais da gestação, mas mesmo assim mandei o meu nome e a documentação para um curso de férias, mas não sabia como se dava o processo da inscrição, ai minha filha nasceu não tinha como vir, desisti do processo. Em 2012 minha sobrinha, Nayara, convidou pra fazer o vestibular, ela pegou o edital e me mostrou, não sabia nada sobre curso, ela me dizia não pegue o mesmo curso que eu, ai ela escolheu ciências sociais e eu ciências naturais. Pra chegar no local da prova foi um sacrifício, saímos numa sexta feira da aldeia, muita chuva, ficamos em Itupiranga, numa casa de apoio que o secretario de educação pagava, dormimos lá para pegar o ônibus no sábado. Mais um ano esperando, no próximo ano foi mais difícil ainda de chegar na cidade, devido as estradas, mas fiz. Estava na aldeia quando minha sobrinha me mandou uma carta dizendo que tinha passado.[... Fiquei muito feliz e ruim, ao mesmo tempo, pois pensava como ia sobreviver na cidade sem dinheiro e com uma filha de dois anos? (Raquel Guajajara. Entrevista, 2016).

Quando aconteceu o primeiro seminário fiquei em dúvida se era isso mesmo que queria, por que não sou de falar em público, de falar em sala de aula e o professor ficar me avaliando, pra eu estar lá tenho que entender o que está sendo lido lá na frente. Será que vou conseguir mesmo? As questões das resenhas e fichamentos...aí tive muitas dificuldades, pensei: "que "diacho" é isso?" Vejo que é diferente, tudo tem que ser nas normas, diferente de quando eu estudava na aldeia (calendário, conteúdo), então não consegui ver essa relação de conhecimento nosso na universidade (Nayara Guajajará. Entrevista, 2016).

Quando um índio chega à universidade, é visto de forma diferente, "esse índio ai ô, eu olho pra ele e parece que não sabe de nada". Mas não sabem a dificuldade, por isso estou pedindo hoje professores qualificados, preparados, para preparar meu povo, para quando ele for para uma faculdade ele saiba onde ele está estudando, onde ele está pisando, ele vai ter visão, ele vai falar. O índio tem que estudar, voltados para nossa comunidade, aprender conhecimento do branco e aplicar dentro da comunidade; e todo indígena tem que ter 0 
mesmo pensamento, estudar, mas não deixar de praticar sua cultura, nem seus costumes. E que a universidade tinha que respeitar, por que o índio era proibido de estudar na quinta série, era permitida só até a quarta série, não podia estudar mais, pois tinha que ser dominado pela FUNAI. Todo mundo tem que estudar, cada ano que passa as coisas vão mudando, vai se criando leis onde algumas vão tirando o direito do índio de ser índio, fazendo dele um cidadão comum, essa é a preocupação, tem que estudar para saber qual o direito que temos quando tiram um pedacinho da nossa terra, quando tiram uma árvore da nossa terra. A terra é nossa mãe, o igarapé nosso pai que nos criou, onde daí sai nosso alimento, então tem que saber falar numa reunião, tem que ter argumento, tem que ter visão. Por isso que quero que cada índio seja advogado, médico, agrônomo, professora, um juiz, chegar a esse patamar de ensino. (Kátia Gavião. Entrevista, 2016).

A universidade aparece carregada de símbolos, de códigos que precisam ser desvendados, nas narrativas acima, notamos a dificuldade inicial de chegada à universidade, aprender as novas linguagens, outros conhecimentos baseados num modelo hierarquizado e excludente.

Nesse contexto, foi importante citar as ferramentas pedagógicas pensadas por Walsh (2009), que diferenciou a interculturalidade crítica e a interculturalidade funcional: a primeira voltada ao reconhecimento de outros, suas formas de ser e estar no mundo, numa lógica de decolonização do saber; e a segunda como a prática política que se cruza com as do saber e do ser, mas homogeneizando esses seres e saberes numa lógica de aceitação, porém, não valorizando os diferentes, privilegiando alguns sobre outros, "naturalizando" a diferença e ocultando as desigualdades que se estruturam e se mantêm em seu interior (WALSH, 2009. p. 13).

Inspirando-nos na lógica epistêmica decolonial, pensamos que essas sensações de estranhamento deveriam:

Questionar continuamente a racialização, subalternização, interiorização e seus padrões de poder, visibiliza maneiras diferentes de ser, viver e saber e busca o desenvolvimento e criação de compreensões e condições que não só articulam e fazem dialogar com as diferenças num marco de legitimidade, dignidade, igualdade, equidade e respeito, mas que - ao mesmo tempo - alentam a criação de modos "outros" - de pensar, ser, estar, aprender, ensinar, sonhar e viver que cruzam fronteira (WALSH, 2009, p. 15).

Assim, estudar foi uma ferramenta de resistência para as mulheres Guajajaras e Gavião, contra a opressão, a invisibilização. Por isso, foi necessário formular outros processos de colonialidade do pensamento, do ser e saber, implicando em outros 
e-Mosaicos - Revista Multidisciplinar de Ensino, Pesquisa, Extensão e Cultura do Instituto de Aplicação Fernando Rodrigues da Silveira (CAp-UERJ)

V. 7 - N. 14 - ABRIL 2018 - ISSN: 2316-9303

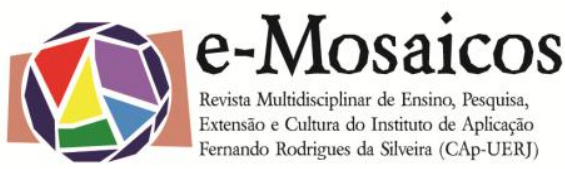

DOI: $10.12957 /$ e-mosaicos.2018.30145

processos de conhecimentos formais que sejam dialogados e não presos às questões eurocêntricas. Presos em somente uma forma de saber, que exclui outros conhecimentos e principalmente outras formas de produção de conhecimentos.

Catherine Walsh (2009) defendeu no campo educacional a abordagem da interculturalidade crítica. Diferente da interculturalidade funcional, que reconhece outras culturas, outros saberes, mas não modifica a estrutura social, a interculturalidade crítica prioriza a problematização da epistemologia moderna ocidental, buscando desestruturar a hierarquia entre saberes.

Assim, visualizamos a diversidade como um desafio às universidades, vislumbrando a necessidade, como assinalou Candau (2009), em perceber a existência de práticas interculturais, diferenciando a interculturalidade crítica da funcional, e se são utilizadas como estratégia de coesão social, assimilando os grupos subalternizados a uma cultura hegemônica ou como construtivas de democracia, capazes de construir novas relações e contribuindo com os projetos societários desses povos (WALSH, 2008; 2006; 2012;2010; 2013).

Para uma melhor compreensão acerca dos conceitos de igualdade, desigualdade e diferença, bem como seus usos, Candau (2009) contribui para o entendimento de que não se deve refutar a igualdade e a diferença, e sim a desigualdade e a padronização de formas de comportamentos, da mecanização de padrões. A essa forma de compreensão em que as diferenças devem ser respeitadas, Santos (2003) afirma: "[...] temos o direito de ser iguais quando a diferença nos inferioriza; temos o direito a ser diferentes quando a igualdade nos descaracteriza" (SANTOS, 2003, p. 56).

$\mathrm{Na}$ mesma direção, fizemos questionamentos relacionados aos distintos lugares de fala e de trajetórias escolares das mulheres indígenas e se esses foram respeitados quando entraram na universidade. Talvez esses aspectos possam ser fundantes para se pensar as diferenças entre os povos que ocupam aquele espaço, refletindo sobre essas diferenças pela presença dos diversos povos indígenas na universidade, que poderiam assinalar como uma possibilidade de romper com a homogeneização, tendo como desdobramentos a possível construção de política de ensino superior indígena que reconhece e trabalha com essas particularidades.

O professor português da Universidade de Coimbra, Boaventura de Souza Santos, nos ajudou a pensar a questão da igualdade na luta coletiva. Levando em consideração as diferenças entre as mulheres Guajajara e a Cacica Kátia, todas adotaram estratégias de sobrevivência nesse mundo que as cerca, onde são diferentes pelas suas trajetórias, mas iguais na participação nas mobilizações por território e na garantia de seus direitos.

Foi possível afirmar que a entrada na universidade causou impactos, tanto nessas mulheres, como na própria instituição, que vai sendo mobilizada a pensar nos desafios postos a essa presença. Tal como a existência de um enquadramento de pensamento e comportamento universal na academia, que produz apenas o modelo colonizador de episteme, provocando implicações não somente aos povos originários, 
e-Mosaicos - Revista Multidisciplinar de Ensino, Pesquisa, Extensão e Cultura do Instituto de Aplicação Fernando Rodrigues da Silveira (CAp-UERJ)

V. 7 - N. 14 - ABRIL 2018 - ISSN: 2316-9303

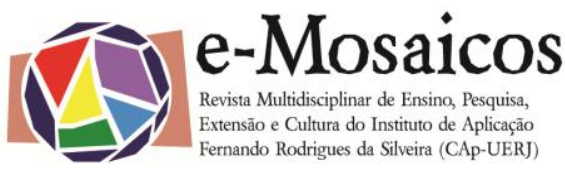

DOI: $10.12957 /$ e-mosaicos.2018.30145

mas estendendo-se também a qualquer estudante na universidade, a qualquer saber que se diferencie do poder circunscrito universal, dominante e a serviço de políticas neoliberais como forma de dominação.

Porém, no caso específico desses estudantes oriundos dos povos originários, assinalamos que o desafio posto às universidades está além de bolsas de apoio e permanência estudantil, como alertou Baniwa:

Não basta disponibilizar sistemas de cotas, mas complementá-las e reforçá-las com projetos e programas que possibilitem o apoio e acompanhamento dos acadêmicos indígenas viabilizando o sucesso em todo o processo de formação. Uma proposta viável seria disponibilizar bolsas de pesquisas que mantenham os alunos indígenas em conexão permanente com sua comunidade durante os estudos, além de ações pedagógicas que reduzam práticas de discriminação, racismo e humilhação de que eles são constantemente vítimas, nas universidades (BANIWA, 2017, p. 20).

A presença dessas mulheres dos povos originários protagonizou as reflexões necessárias referentes às práticas tidas como normais, forçando o desvelar de práticas de discriminação e racismo experienciadas por homens e mulheres de povos originários, não somente no espaço acadêmico como também pelas imagens que aprisionam identidades e culturas buscando 'moldar uma única forma de comportamento e estereótipos, provocando racismos epistêmicos, não reconhecendo o outro como ser inteiramente humanos' (MALDONADO-TORRES, 2008, p. 79).

\section{CONSIDERAÇÕES FINAIS}

Pensar a permanência das mulheres de povos originários na universidade é um desafio relacionado à cultura, a outras formas de conhecimento, aos corpos que ali se fazem presentes como resistências, e que, de certa forma, assumem suas identidades e fortalecem seus povos, seu sentimento de pertencimento a um povo.

A escolha da análise a partir de autores decoloniais nos levou às reflexões sobre os conhecimentos tidos como universais; sobre as diferentes culturas que estão em movimento; sobre a desmistificação relacionada à interculturalidade funcional que possibilita o acesso ao ensino superior sem garantias especificas; sobre a permanecia dessas mulheres, que são autoras de suas próprias histórias e vão demandando, desvelando e inquietando, a partir de suas resistências, o que poderia ser tido como normal

Suas narrativas aqui apresentadas evidenciam as estratégias de resistências criadas a partir dificuldades enfrentadas por essas mulheres indígenas nesse universo no qual se apresentam e ocupam. Isso provoca reflexões necessárias para além da entrada, nos cursos de graduação, mas de sua permanência neles; levando 
DOI: $10.12957 /$ e-mosaicos.2018.30145

as universidades a se questionarem e repensarem suas bases epistemológicas universais, para que essas mulheres superem a mancha de serem tidas como bestiais e/ou incapazes de estarem nesse espaço que lhes é de direito.

Dessa forma, damos uma salva às guerreiras Guajajará e à Cacica Kátia: sejam bem-vindas, com suas narrativas e histórias, gritando que estão resistindo, cada uma a seu tempo, da sua forma, fazendo história por onde passam, pegando suas "flechas" como elemento metafórico de (re)existência.

\section{REFERÊNCIAS}

BANIWA, Gersem. A lei das cotas e os povos indígenas: mais um desafio para a diversidade. Cadernos do Pensamento Crítico Latino-Americano. Disponível em: < http://flacso.redelivre.org.br/files/2014/12/XXXVcadernopensamentocritico.pdf>. Acesso em: 21 de abril de 2017.

BENJAMIN, Walter. Origem do drama trágico alemão. Belo Horizonte: Autêntica, 2011.

BENJAMIN, Walter. Sobre o conceito de História. In: BENJAMIN, Walter. Magia e técnica, arte e política: ensaios sobre literatura e história da cultura. 7a ed. São Paulo: Brasiliense,1994.

BENJAMIN, Walter. Sobre o conceito de história. In: Magia e técnica, arte e política: ensaios sobre a literatura e história da cultura. $2^{\mathrm{a}}$ ed. São Paulo: Brasiliense, 2012.

BHABHA, Homi K. O local da cultura. Belo Horizonte: Ed. UFMG, 2013.

CANDAU, Vera Maria. Educação intercultural na América latina: entre concepções, tensões e propostas. Rio de Janeiro: 7 Letras, 2009.

DUSSEL, Enrique. Meditações anti-cartesianas: sobre a origem do anti-discurso filosófico da modernidade. In: SANTOS, Boaventura de Sousa; MENESES, Maria Paula. (Orgs.). Epistemologias do Sul. São Paulo: Cortez, 2010.

FANON, Frantz. Pele negra, máscaras brancas. Salvador: EDUFBA, 2008.

FRANÇA, Cyntia Simioni. O canto da odisseia e as narrativas docentes. dois mundos que dialogam na produção de conhecimento histórico educacional. Tese (Doutorado) - Faculdade de Educação, Universidade Estadual de Campinas, Campinas. 2015.

GALZERANI, Maria Carolina Bovério. Imagens que lampejam: contribuições de Walter Benjamin para a produção de conhecimentos históricos. Encuentro de saberes. Luchas populares, resistências Y educación. v. 1, p. 53, 2013. 
GAUTHIER. Jacques. A sociopoética como prática de pesquisa integral. Ver. Enferm. UERJ, Rio de Janeiro, 2014 nov/dez; 22(6):848-52.

LUGONES, Maria. Rumo a um feminismo descolonial. Estudos Feministas. v. 22, n. 3, 2015.

MALDONADO-TORRES, Nelson. A topologia do ser e a geopolítica do conhecimento. Modernidade, império e colonialidade. Revista crítica de Ciências Sociais. n. 80, p. 71-114, 2008.

MIGNOLO, Walter D. Colonialidad global, capitalismo y hegemonía epistémica. Indisciplinar las ciencias sociales: geopolíticas del conocimiento y colonialidad del poder. Perspectivas desde lo andino, p. 215, 2002.

PAIM, Elison Antonio. Memórias e experiências do fazer-se professor. Tese (Doutorado) - Faculdade de Educação, Universidade Estadual de Campinas, Campinas. 2005.

ROSA, Maria Inês Petrucci et al. Uma outra compreensão de currículo. Currículo sem fronteiras. v. 11, n. 1, p. 198-217, 2011.

ROSA, Maria Inês Petrucci. Currículo e narrativa: potencialidades das mônadas para uma outra compreensão dos acontecimentos educativos. In: MACEDO, Elizabeth; MACEDO, Roberto Sidnei; AMORIM, Antonio Carlos (orgs.). Discurso, texto, narrativa nas pesquisas em currículo. Campinas, SP: FE/UNICAMP, 2009

SANTOS, Boaventura de Sousa. Reconhecer para libertar: os caminhos do cosmopolitanismo multicultural. Rio de Janeiro: Civilização Brasileira, 2003.

SPIVAK, Gayatri Chakravorty. Pode o subalterno falar? Belo Horizonte: Editora UFMG, 2010.

WALSH, Catherine. Interculturalidad crítica y educación intercultural. Construyendo interculturalidad crítica, p. 75-96, 2010.

. Interculturalidad y (de)colonialidad: Perspectivas críticas y políticas. Visão Global. Joaçaba, v. 15, n. 1-2, p. 61-74, jan./dez. 2012.

.Interculturalidad, estado, sociedad. Luchas (de)coloniales de nuestra época. Quito: Universidad Andina Simón Bolívar: ABYA YALA, 2009

Interculturalidad, plurinacionalidad y decolonialidad: las insurgencias político -epistémicas de refundar el Estado. In: Tábula Rasa. Bogotá - Colômbia, No.9: 131152, julio-diciembre 2008. 
Lo pedagógico y lo decolonial: entretejiendo caminhos. Pedadodías decoloniales: prácticas insurgentes de resistir, (re)existir y (re)vivir. Tomo I. Quito, Ecuador: Ediciones Abya-Yala, 2013, p. 23-68

\section{FONTES ORAIS}

Nayane Guajajara. Entrevista concedida à Tatiana de Oliveira Santana. Marabá, Pará. 20 de fevereiro de 2016.

Nayara Guajajara. Entrevista concedida à Tatiana de Oliveira Santana. Marabá, Pará. 21 de fevereiro de 2016.

Raquel Guajajara. Entrevista concedida à Tatiana de Oliveira Santana. Marabá, Pará. 21 de fevereiro de 2016

Kátia Gavião. Entrevista concedida à Tatiana de Oliveira Santana. Marabá, Pará. 01 de março de 2016. 